\title{
Erratum to: Effects of Thermoelectric Magnetic Convection on the Solidification Structure During Directional Solidification under Lower Transverse Magnetic Field
}

\author{
XI LI, ZHONGMING REN, ANNIE GAGNOUD, OLGA BUDEBKOVA, \\ YVES FAUTRELLE, and WEI LI REN
}

DOI: $10.1007 / \mathrm{s} 11661-011-1038-8$

(C) The Minerals, Metals \& Materials Society and ASM International 2011

Erratum to: METALLURGICAL AND MATERIALS

TRANSACTIONS A, Vol. 42A, No. 11,

November 2011, pp. 3459-71

DOI: $10.1007 / \mathrm{s} 11661-011-0741-9$

\section{REFERENCE}

22. J.W. Dong, Z.M. Ren, W.L. Ren, X. Li, and X. Li: Acta Metall. Sin., 2010, vol. 46 (1), p. 71.

FOLLOWING are corrections to the original article: Wei Li Ren is the sixth author.

Revised caption for Fig. 10(d) is: The longitudinal structure with the $0.7 \mathrm{~T}$ magnetic field. ${ }^{[22]}$

XI LI and ZHONGMING REN, Professors, and WEI LI REN, Associate Professor, are with the Department of Material Science and Engineering, Shanghai University, Shanghai 200072, People's Republic of China. Contact e-mail: xi@hmg.inpg.fr ANNIE GAGNOUD and OLGA BUDEBKOVA, Researchers, and YVES FAUTRELLE, Professor, are with SIMAP-EPM-Madylam/G-INP/CNRS, PHELMA, BP 75, 38402 St Martin d'Heres Cedex, France.

The online version of the original article can be found under doi:10.1007/s11661-011-0741-9.

Article published online December 9, 2011 